\title{
SÍNTESEECARACTERIZAÇÃODENANOPARTÍCULAS DE PRATA NO POLIELETRÓLITO CLORETO DE 3-N-PROPILPIRIDÍNIO SILSESQUIOXANO PARA APLICAÇÃO EM MATERIAIS TÊXTEIS
}

\author{
SYNTHESIS AND CHARACTERIZATION OF SILVER \\ NANOPARTICLES IN THE POLYMER 3-N-PROPYL \\ PYRIDINE SILSESQUIOXANE CHLORIDE FOR \\ APPLICATION IN TEXTILE MATERIALS
}

\author{
Alan F. Y. Matsushita* \\ Juliana Inaba* \\ Sérgio T. Fujiwara* \\ Karen Wohnrath* \\ Jarem R. Garcia* \\ Christiana A. Pessoa*
}

\begin{abstract}
RESUMO
No presente trabalho foi realizada a síntese e a caracterização das nanopartículas de prata (AgNps), utilizando-se o polieletrólito cloreto de 3-n-propilpiridínio silsesquioxano $\left(\mathrm{SiPy}^{+} \mathrm{Cl}^{-}\right)$como nanoreator e a aplicação dessas nanopartículas para incorporação em materiais têxteis. As sínteses das AgNps foram realizadas pelo método de precipitação, utilizando-se $\mathrm{o} \mathrm{AgNO}_{3}$ como precursor, o polieletrólito $\left(\mathrm{SiPy}^{+} \mathrm{Cl}^{-}\right)$como estabilizante e o $\mathrm{NaBH}_{4}$ como agente redutor. A síntese foi realizada em quatro proporções $(1 \%, 2 \%, 5 \%$ e $10 \% \mathrm{~m} / \mathrm{V}$ de prata em relação ao polieletrólito) e a formação, estabilidade e tamanho das nanopartículas foram analisadas por espectroscopia de UV-Vis e Potencial Zeta. Observou-se que na presença do $\mathrm{SiPy}^{+} \mathrm{Cl}^{-}$, a banda plasmônica das $\mathrm{AgNps}$, na região de 350$450 \mathrm{~nm}$, apresentou-se deslocada para maiores comprimentos de onda, o que pode estar associado à interação do $\mathrm{SiPy}^{+} \mathrm{Cl}^{-} \mathrm{com}$ as $\mathrm{AgNps}$ ou à diferença de tamanho das nanopartículas estabilizadas em relação as AgNps livres. As nanopartículas obtidas nas proporções $5 \%$ e $10 \% \mathrm{~m} / \mathrm{V}$ apresentaram-se mais estáveis, com tamanhos médios de aproximadamente 25 a $45 \mathrm{~nm}$. A partir dos espectros de infravermelho com transformada de Fourier (FTIR), pode-se constatar um decréscimo na intensidade das bandas em $1634 \mathrm{e} 1484 \mathrm{~cm}^{-1}$ referente às vibrações do anel piridínio após a incorporação das AgNps, evidenciando interações entre eles. O tamanho médio dos cristalitos, calculado pela equação de Scherer, foi de $42 \mathrm{~nm}$ e $48 \mathrm{~nm}$ para as amostras com $10 \%$ e $5 \%$ de prata, respectivamente. A atividade antimicrobiana das AgNps impregnadas em tecidos de algodão foi avaliada e apresentou resultados promissores na inibição do crescimento bacteriano e fúngico.
\end{abstract}

Palavras-chave: Nanopartículas de prata. Silano. Materiais têxteis. Atividade antimicrobiana.

\footnotetext{
"Departamento de Química, Universidade Estadual de Ponta Grossa, UEPG, PR, Brasil.
} 


\begin{abstract}
This paper describes the synthesis and characterization of silver nanoparticles (AgNps), using the polyelectrolyte 3-n-propylpyridinium silsesquioxane chloride $\left(\mathrm{SiPy}^{+} \mathrm{Cl}^{-}\right)$as a nanoreactor and the application of these nanoparticles for incorporation into textile materials. The AgNps syntheses were performed by the precipitation method, using $\mathrm{AgNO}_{3}$ as the precursor, $\mathrm{SiPy}^{+} \mathrm{Cl}^{-}$as the stabilizer and $\mathrm{NaBH}_{4}$ as reducing agent. The synthesis was performed using different ratios between $\mathrm{Ag} / \mathrm{SiPy}^{+} \mathrm{Cl}^{-}(1 \%, 2 \%, 5 \%$ and $10 \% \mathrm{w} / \mathrm{v})$ and the formation, stability and size of the nanoparticles were analyzed by UV-Vis spectroscopy and Zeta Potential. It was observed that in the presence of $\mathrm{SiPy}^{+} \mathrm{Cl}^{-}$, the plasmon band of AgNps, in the region of 350-450 nm, shifted to longer wavelengths, which may be associated with the interaction between $\mathrm{SiPy}^{+} \mathrm{Cl}^{-}$and $\mathrm{AgNps}$ or the difference in size of the stabilized nanoparticles in relation to the free AgNps. The nanoparticles obtained using the proportions $5 \%$ and $10 \% \mathrm{w} / \mathrm{v}$ were more stable, with average sizes of approximately 25 to $45 \mathrm{~nm}$. From the Fourier transform infrared spectra (FTIR), a decrease in the intensity of the bands at 1634 and 1484 $\mathrm{cm}^{-1}$ could be observed, which was related to the vibrations of the pyridinium ring, after incorporation of $\mathrm{AgNps}$, which is evidence of the interaction between them. The average crystallite size, calculated by the Scherer equation, was 42 $\mathrm{nm}$ and $48 \mathrm{~nm}$ for the samples with $10 \%$ and $5 \%$ of silver, respectively. The antimicrobial activity of the AgNps impregnated in cotton was evaluated and gave promising results in the inhibition of bacterial and fungal growth.
\end{abstract}

Keywords: Silver nanoparticles. Silane. Textiles. Antimicrobial activity.

\section{Introdução}

A maior parte dos tecidos têxteis produzidos com fibras naturais, assim como os manufaturados com fibras sintéticas, não são resistentes ao crescimento de bactérias ou fungos patogênicos. Dessa forma, com o objetivo de melhorar a qualidade de vida dos seres humanos, uma nova área tem se desenvolvido no domínio dos acabamentos têxteis, principalmente no que se refere ao crescimento de micro-organismos (FEITOR, 2010).

Os materiais têxteis produzidos com fibras naturais são um excelente meio para a proliferação de micro-organismos, particularmente bactérias e fungos, devido ao fato de permitirem a retenção de umidade e agirem como fontes de nutrientes para esses seres vivos. $\mathrm{O}$ crescimento de micro-organismos em têxteis causa efeitos indesejáveis não só no tecido, mas também para o usuário (FEITOR, 2010).

Agentes antimicrobianos são utilizados para prevenir três efeitos indesejáveis na indústria têxtil: fenômenos de degradação, como corantes, coloração e deterioração de fibras; o odor desagradável que as bactérias podem causar; e o aumento do potencial de riscos de infecções para a saúde (FEITOR, 2010; DASTJERDI; MONTAZER, 2010).

Recentemente, a incorporação de nanopartículas de prata em tecidos tem recebido grande atenção, devido suas propriedades, como alto poder biocida e grande área superficial, é o material inorgânico mais tóxico para os micro-organismos e menos tóxico para as células humanas (FEITOR, 2010; DASTJERDI; MONTAZER, 2010; ELRAFIE et al., 2012; ILIC et al., 2009). Na literatura já existem alguns métodos de incorporação de nanopartículas de prata, estudados por exemplo por (ILIC et al., 2009), que imobilizou nanopartículas de prata em algodão via adsorção superficial e (CHEN; CHIANG, 2008), que utilizaram monômeros quelatos com nanopartículas de prata adsorvidas ligados às fibras de algodão, os quais apresentam forte atividade biocida. 
$\mathrm{Na}$ presente pesquisa, a incorporação das nanopartículas de prata foi realizada utilizando o método Layer-by-Layer ( $L b L$ ), cuja técnica fornece filmes de espessura nanométrica com alta homogeneidade (SANTOS et al., 2012; DECHER et al., 1994; PENG et al., 2009). Esta técnica apresenta várias vantagens para a incorporação de nanopartículas em tecidos, como o alto controle molecular das nanopartículas adsorvidas, interação via adsorção eletrostática dos polieletrólitos utilizados e também a possibilidade de incorporação de duas ou mais espécies de nanopartículas no mesmo tecido, atribuindo assim, propriedades de interesse ao tecido.

Atualmente, tem-se investigado as propriedades de nanocompósitos híbridos de NPs metálicas incorporadas às matrizes poliméricas. Estas moléculas contêm cavidades internas com escala nanométrica, que podem servir para a síntese de nanopartículas metálicas (SANTOS et al., 2012). No trabalho de (SANTOS et al.,2012) o policátion cloreto de 3-n propilpiridínio silsesquioxano $\left(\mathrm{SiPy}^{+} \mathrm{Cl}^{-}\right)$foi utilizado como template da síntese de nanopartículas de platina, as quais apresentaram tamanho médio entre $3 \mathrm{~nm}$ e $40 \mathrm{~nm}$, apresentando uma alta estabilidade e mostrando ser um ótimo polieletrólito para síntese de suspensões de nanopartículas.

Neste trabalho, também utilizou-se o policátion cloreto de 3-n propilpiridínio silsesquioxano $\left(\mathrm{SiPy}^{+} \mathrm{Cl}^{-}\right)$como nanoreator para crescimento das nanopartículas de prata $\left(\mathrm{Ag} / \mathrm{SiPy}^{+} \mathrm{Cl}^{-}\right)$com a finalidade de obter filmes LbL alternados com o poliânion poliestireno sulfonato (PSS). A incorporação do nanocompósito foi realizada em fibras de algodão previamente tratadas com o objetivo de melhorar a interação entre a superfície do tecido e o nanocompósito. As fibras de algodão com o nanocompósito foram caracterizadas por MEV e a atividade antibacteriana dos nanocompósitos incorporadas às fibras de tecido foi investigada por inibição de crescimento bacteriano ou atividade bactericida, evidenciado pela formação de colônias em meio sólido e líquido.

\section{Materiais e métodos}

Nitrato de prata $\left(\mathrm{AgNO}_{3}\right)$ e borohidreto de sódio $\left(\mathrm{NaBH}_{4}\right)$ foram adquiridos da empresa Vetec, nitrito de sódio $\left(\mathrm{NaNO}_{2}\right)$, ácido nítrico $\left(\mathrm{HNO}_{3}\right)$ e ácido fosfórico $\left(\mathrm{H}_{3} \mathrm{PO}_{4}\right)$ foram adquiridos da empresa
Synth, todos os reagentes foram utilizados sem purificação prévia. As amostras do tecido $100 \%$ algodão foram adquiridas em uma loja de tecidos local.

A síntese do nanohíbrido $\mathrm{Ag}-\mathrm{SiPy}^{+} \mathrm{Cl}^{-}$foi realizada com $20 \mathrm{~mL}$ da solução aquosa de $\mathrm{SiPy}^{+} \mathrm{Cl}^{-} 12$ $\mathrm{g} \mathrm{L}^{-1}, 20 \mathrm{~mL}_{\text {de }} \mathrm{NaBH}_{4}$ usado como agente redutor e $20 \mathrm{~mL}$ de $\mathrm{AgNO}_{3}$. A síntese foi realizada em quatro proporções: $1 \%, 2 \%, 5 \%$ e $10 \%(\mathrm{~m} / \mathrm{V})$ de prata em relação ao polieletrólito $\mathrm{SiPy}^{+} \mathrm{Cl}^{-}$, a concentração do $\mathrm{NaBH}_{4}$ foi usada em $10 \%$ de excesso sobre a concentração de prata. As nanopartículas de prata foram sintetizadas gotejando-se lentamente a solução de $\mathrm{AgNO}_{3}$ sobre solução de $\mathrm{NaBH}_{4}$ com o polieletrólito $\mathrm{SiPy}^{+} \mathrm{Cl}^{-}$sob agitação à temperatura ambiente de aproximadamente $25^{\circ} \mathrm{C}$.

Primeiramente as suspensões de nanopartículas de prata $\mathrm{Ag}-\mathrm{SiPy}^{+} \mathrm{Cl}^{-}$foram liofilizadas no Liofilizador Terroni LD 1500, a fim de realizar medidas de FTIR, Raman e Difração de Raios X.

A formação e a qualidade dos cristalitos formados foram analisadas por Difração de Raios X (DRX). Os difratogramas de Raios X foram obtidos com as amostras liofilizadas com o difratômetro X-ray Diffractometer Rigaku Ultima IV com as condições de medida: radiação $\mathrm{Cu}-\mathrm{k} \alpha\left(\lambda=1.5418 \mathrm{~A}^{\circ}\right)$ com entre $2 \theta$ entre $5^{\circ}$ e $120^{\circ}$ a uma velocidade de varredura de $2^{\circ}$ por minuto

As análises de espectroscopia de infravermelho transformada de Fourier (FTIR) foram realizadas no modo de transmissão em pastilhas de $\mathrm{KBr}$ com as amostras liofilizadas de $\mathrm{Ag}-\mathrm{SiPy}^{+} \mathrm{Cl}^{-}$utilizando o Espectrofotômetro SHIMADZU FTIR Prestige - 21 na faixa de 400 a $4000 \mathrm{~cm}^{-1}$ com uma resolução de 4 $\mathrm{cm}^{-1} \mathrm{e}$ número de varreduras de 64 .

A formação e o estado de agregação do nanohíbrido foi acompanhada por espectroscopia UV-Vis (Varian Cary 50 Bio) na faixa de 200 a $800 \mathrm{~nm}$. A distribuição de tamanho das partículas e o Potencial Zeta foram analisados pelo Zetasizer Nano-Zs90 - Nanoseries.

Para haver a incorporação do nanohíbrido Ag/ $\mathrm{SiPy}^{+} \mathrm{Cl}^{-}$pelo método Layer-by-Layer realizou-se um tratamento químico na superfície do tecido de algodão a fim de gerar celulose oxidada na superfície e assim criar uma adsorção eletrostática do híbrido no tecido. Nesse tratamento utilizou-se $\mathrm{HNO}_{3}$ e $\mathrm{H}_{3} \mathrm{PO}_{4}$ na proporção de $2: 1$, respectivamente, na concentração de 0,1 mol.L-1 para ambos, $\mathrm{NaNO}_{2}$ na proporção 
de $1.4 \%(\mathrm{~m} / \mathrm{V}) . \mathrm{O} \mathrm{H}_{3} \mathrm{PO}_{4}$ atua como catalisador da reação e o $\mathrm{NaNO}_{2}$ como ativador da reação, similar ao descrito na literatura (KUMAR;YANG, 2002).

Para o crescimento dos filmes nos tecidos de algodão, foram utilizadas as amostras contendo 5\% e $10 \%$ de prata, as quais apresentaram melhores resultados quanto à estabilidade das nanopartículas. Os filmes foram construídos alternando-se o nanocompósito $\mathrm{Ag}-\mathrm{SiPy}^{+} \mathrm{Cl}^{-}$com uma solução de poliestireno sulfonato (PSS) a 4 g.L $\mathrm{L}^{-1}$, em um total de 10 bicamadas. Como solução de lavagem, utilizou-se água destilada em $\mathrm{pH}=7,0$ e, após o crescimento das bicamadas sonificou-se o tecido em água para a retirada das partículas que não adsorveram eletrostaticamente. As amostras foram secadas em estufa a $45^{\circ} \mathrm{C}$.

As fibras de algodão foram caracterizadas por espectroscopia FTIR com o objetivo de verificar se o tratamento químico realizado no tecido causou alguma modificação nas propriedades das fibras. A análise foi realizada em pastilhas de $\mathrm{KBr}$, utilizando o Espectrofotômetro SHIMADZU FTIR Prestige 21 na faixa de 400 a $4000 \mathrm{~cm}^{-1}$, com uma resolução de $4 \mathrm{~cm}^{-1}$ e número de varreduras de 64 .

A morfologia do nanohíbrido $\mathrm{Ag} / \mathrm{SiPy}+\mathrm{Cl}-$ revestido nas fibras de algodão foi examinado por microscopia eletrônica de varredura (MEV, Shimadzu SSX-550, operando a $15 \mathrm{keV}$ ).
Os corpos de prova contendo tecidos de algodão não estéreis com e sem modificação por incorporação de nanopartículas de prata nas concentrações de $1 \%, 2 \%, 5 \%$ e $10 \%$ foram incubados em meio líquido LB Luria Broth, previamente inoculados com uma colônia isolada de $E$. coli estirpe DH5a. Os frascos de cultura foram mantidos sob agitação a $120 \mathrm{rpm}$ e $37^{\circ} \mathrm{C}$, durante $48 \mathrm{~h}$. Após esse período, a densidade óptica das culturas foi avaliada em Espectrofotômetro UV-Vis (Varian Cary 50 Bio), em $600 \mathrm{~nm}$. Para avaliar o efeito bacteriostático/bactericida, amostras das culturas obtidas foram coletadas por palitos de madeira e reinoculadas em meio sólido LA (SAMBROOK et al., 1989) e mantidos a $37^{\circ} \mathrm{C}$, durante $24-48 \mathrm{~h}$. O crescimento bacteriano foi avaliado pela formação de unidade formadoras de colônia, UFC, após este período.

\section{Resultados e discussão}

Síntese e Caracterização das AgNps incoporadas no $\mathrm{SiPy}^{+} \mathrm{Cl}^{-}$

$\mathrm{Na}$ síntese de nanopartículas de prata coloidal, o polieletrólito $\mathrm{SiPy}^{+} \mathrm{Cl}^{-}$foi utilizado como um agente estabilizador para a formação de nanopartículas de Ag obtidas por redução dos íons Ag a partir de nitrato de prata $\left(\mathrm{AgNO}_{3}\right)$, com $\mathrm{NaBH}_{4}$, de acordo com procedimento similar ao descrito na literatura. (SANTOS et al., 2012). O esquema da incorporação de nanopartículas de prata em $\mathrm{SiPy}^{+} \mathrm{Cl}^{-}$é mostrado na Figura 1(SANTOS et al., 2012).

Figura 1- Esquema da incorporação de nanopartículas de prata em $\mathrm{SiPy}^{+} \mathrm{Cl}^{-}$.

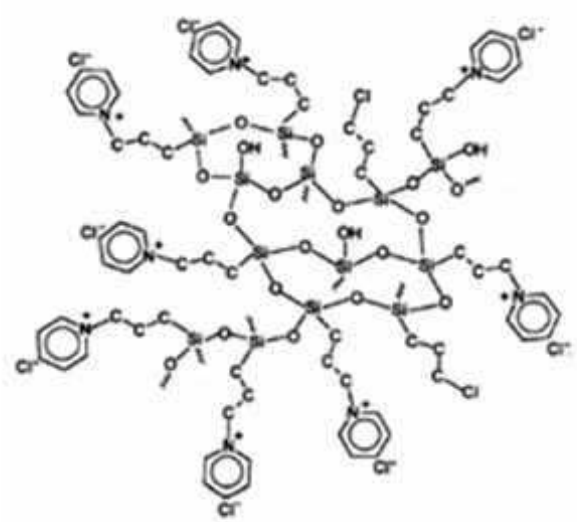

$\mathrm{SiPy}^{+} \mathrm{Cl}^{-}$
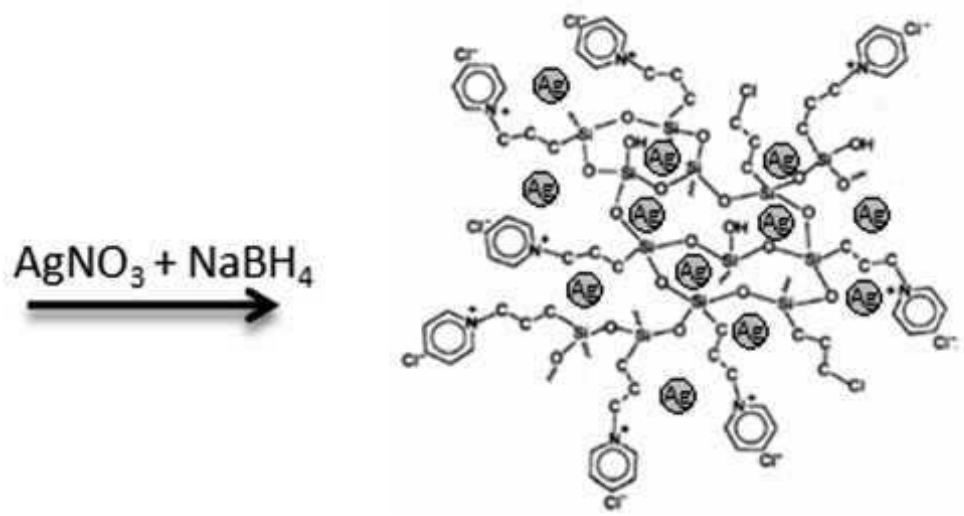

$\mathrm{Ag} / \mathrm{SiPy}^{+} \mathrm{Cl}^{-}$

A reação ocorrida é descrita na equação 1 (SONG et al., 2009).

$\mathrm{Ag}^{+}+\mathrm{BH}^{-}+3 \mathrm{H}_{2} \mathrm{O} \rightarrow \mathrm{Ag}^{o}+\mathrm{B}(\mathrm{OH})_{3}+3.5 \mathrm{H}_{2}$ 
A nucleação e o crescimento das partículas estão diretamente ligados ao agente de redução e estabilizante, além das condições da reação, como a temperatura e o $\mathrm{pH}$. Fortes agentes redutores, tais como borohidreto de sódio, induzem à formação de centros de nucleação que formam pequenos clusters cujo tamanho final depende do estabilizador utilizado (GARCIA, 2011). No entanto, o excesso de agente redutor também pode ajudar na estabilidade, devido à carga elétrica formada nas nanopartículas (GARCIA, 2011). Por conta disso, a ordem de adição de reagentes influencia a estabilidade das nanopartículas formadas. No presente estudo, o $\mathrm{SiPy}^{+} \mathrm{Cl}^{-}$foi utilizado como um estabilizador e o $\mathrm{NaBH}_{4}$ (borohidreto de sódio) como agente redutor. . Foi observado experimentalmente que a solução de $\mathrm{AgNO}_{3}$ deve ser gotejada à solução de $\mathrm{NaBH}_{4}$ contendo $\mathrm{SiPy}^{+} \mathrm{Cl}^{-}$para ocorrer a nucleação e formação de partículas menores e estabilizadas, caso contrário as partículas tendem a se agregar. (SONG, 2009; GARCIA, 2011; LIU et al., 2007).

Na Figura 2A, são mostrados os espectros de UV-Vis das AgNps obtidas a partir da síntese na presença e ausência do polieletrólito $\mathrm{SiPy}^{+} \mathrm{Cl}^{-}$.

Figura 2 - Espectros de absorção UV-Vis das AgNps preparadas via redução com $\mathrm{AgNO}_{3}(\mathrm{~A})$ na presença e ausência do polieletrólito $\mathrm{SiPy}^{+} \mathrm{Cl}^{-}$e (B) com diferentes percentagens de $\mathrm{AgNO}_{3}$ na presença do polieletrólito $\mathrm{SiPy}^{+} \mathrm{Cl}^{-}$.

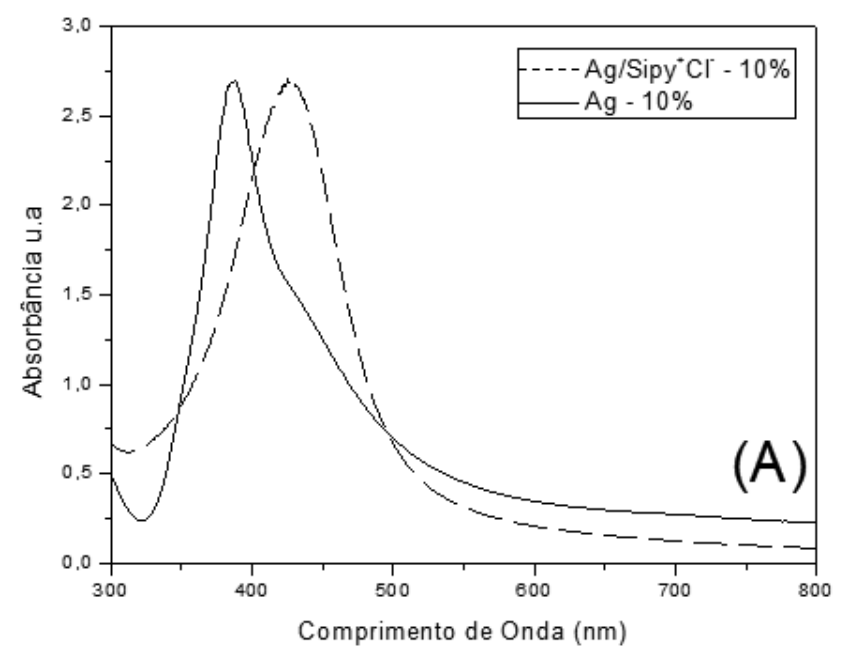

Pode-se notar que com a presença do $\mathrm{SiPy}^{+} \mathrm{Cl}^{-}$, a banda plasmônica das $\mathrm{AgNps}$, observada na região de 350-450 nm, é deslocada para maiores comprimentos de onda. Tal fato pode estar associado tanto à interação polímero com as AgNps, que gera mudanças na banda plasmônica ressonante, ou à diferença de tamanho das nanopartículas entre os sistemas, revelando que possivelmente as nanopartículas estabilizadas mostraram um maior tamanho que as AgNps livres. (NETO, 2010). Porém, foi observado que alguns minutos após a síntese, as partículas de prata sintetizadas na ausência do $\mathrm{SiPy}^{+} \mathrm{Cl}^{-}$agregaram-se e não se mantiveram suspensas na solução. A Figura 2B mostra os espectros de UV-Vis das nanopartículas de prata coloidais preparadas com diferentes percentagens de prata em relação ao polieletrólito $\mathrm{SiPy}^{+} \mathrm{Cl}^{-}(1 \%, 2 \%, 5 \%$ e $10 \%$ de $\mathrm{Ag}-$ $-\mathrm{SiPy}^{+} \mathrm{Cl}^{-} \mathrm{m} / \mathrm{V}$. Para todas as sínteses realizadas, a

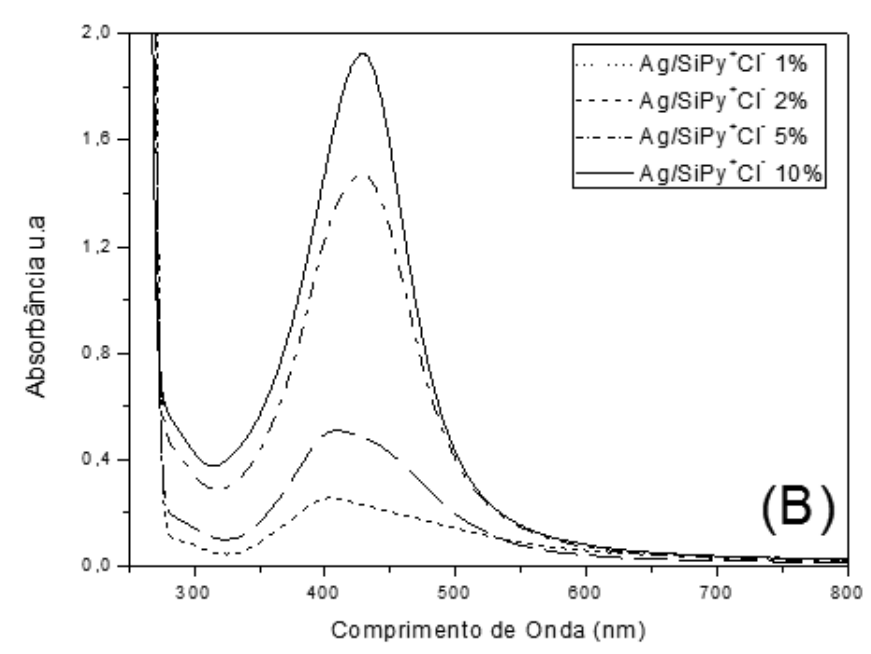

concentração do agente redutor utilizada foi de $10 \%$ em excesso em relação à concentração de prata, para assegurar que todos os íons $\mathrm{Ag}^{+}$fossem reduzidos. Pode ser constatado na Figura 2B, que com o aumento na concentração de $\mathrm{AgNO}_{3}$ utilizada na síntese, maior é o pico de absorção, devido à maior quantidade de AgNps formadas. Para as sínteses de 1\% e $2 \%$ de prata, o espectro mostrou bandas mais largas e deslocadas para menores comprimentos de onda. Tal comportamento sugere que as partículas formadas nessas condições a princípio exibem um menor tamanho, no entanto, apresentam um maior grau de agregação. Por outro lado, as sínteses contendo 5\% e $10 \%$ de prata apresentaram picos mais definidos, em cerca de $430 \mathrm{~nm}$, o que indica um melhor o grau de dispersão das nanopartículas (SONG et al., 2009; GARCIA, 2011). 
Esse fato também pode ser observado pela análise do Potencial Zeta, como mostrado na Tabela 1 . Pode ser constatado que as sínteses realizadas com as proporções de $1 \%$ e $2 \%$ de prata apresentaram um Potencial Zeta negativo próximo à zero, indicando uma baixa estabilidade da suspensão. Já as nanopartículas sintetizadas nas proporções de 5\% e $10 \%$ de prata mostraram valores de Potencial Zeta positivos próximos a 30 , o que indica uma alta estabilidade. (SCHAFFAZICK et al., 2003). A Tabela 1 mostra ainda o tamanho médio das partículas, antes e após a liofilização.

Tabela 1 - Valores de potencial zeta e tamanho médio das partículas das amostras.

\begin{tabular}{c|c|c|c}
\hline Amostra & Potencial Zeta $(\mathrm{mV})$ & $\begin{array}{c}\text { Tamanho Médio } \\
(\mathrm{nm})\end{array}$ & $\begin{array}{c}\text { Tamanho Médio após a } \\
\text { liofilização (nm) }\end{array}$ \\
\hline $\mathrm{Ag}-\mathrm{SiPy}^{+} \mathrm{Cl}^{-}-1 \%$ & $-15,49$ & 25 & 42 \\
\hline $\mathrm{Ag}-\mathrm{SiPy}^{+} \mathrm{Cl}^{-}-2 \%$ & $-0,76$ & 25 & 30 \\
\hline $\mathrm{Ag}-\mathrm{SiPy}^{+} \mathrm{Cl}^{-}-5 \%$ & 27,48 & 35 & 45 \\
\hline $\mathrm{Ag}-\mathrm{SiPy} \mathrm{Cl}^{-}-10 \%$ & 38,92 & 25 & 34 \\
\hline
\end{tabular}

Para as amostras contendo 5\% e 10\% de prata, não houve uma diferença significativa do tamanho médio das partículas antes e após a liofilização. As amostras contendo $1 \%$ e $2 \%$ de prata exibiram um maior número de partículas, com tamanho de $25 \mathrm{~nm}$ e $18 \mathrm{~nm}$, respectivamente, enquanto as amostras contendo $5 \%$ e $10 \%$ de prata apresentaram tamanho médio entre $25 \mathrm{~nm}$ e $35 \mathrm{~nm}$, respectivamente. No entanto, as amostras contendo $1 \%$ e $2 \%$, apesar de possuírem dimensões inferiores, exibiram uma menor estabilidade. Este fato pode também ser constatado pela diferença de tamanho das partículas ressuspendidas, as quais apresentaram um aumento de cerca de $17 \mathrm{~nm}$, enquanto as partículas de amostras contendo $5 \%$ a $10 \%$ tiveram um crescimento de 5 $\mathrm{nm}$ e $10 \mathrm{~nm}$, respectivamente. Ressalta-se ainda que nas amostras contendo $5 \%$ e $10 \%$, o tamanho das nanopartículas foi mais homogêneo, pois como visto em um gráfico da distribuição de tamanho (não mostrado), as amostras contendo 5\% e 10\% apresentam uma menor distribuição de tamanho.

O estudo das interações das nanopartículas de prata com o polieletrólito $\mathrm{SiPy}^{+} \mathrm{Cl}^{-}$foi investigado por espectroscopia FTIR e Raman, pela comparação entre o espectro do polieletrólito puro e após a inclusão das nanopartículas. Para a realização destas análises utilizou-se as amostras liofilizadas. Os espectros de FTIR e Raman do polieletrólito e os nanocompósitos são mostrados na Figura 3.

Figura 3 - (a) Espectro de infravermelho e (b) Raman das amostras liofilizadas de $\mathrm{SiPy}^{+} \mathrm{Cl}^{-}, \mathrm{Ag} / \mathrm{SiPy}^{+} \mathrm{Cl}^{-}-1 \%$, $\mathrm{Ag} / \mathrm{SiPy}{ }^{+} \mathrm{Cl}^{-}-2 \%, \mathrm{Ag} / \mathrm{SiPy}^{+} \mathrm{Cl}^{-}-5 \%$ e $\mathrm{Ag} / \mathrm{SiPy}^{+} \mathrm{Cl}^{-}-10 \%$.
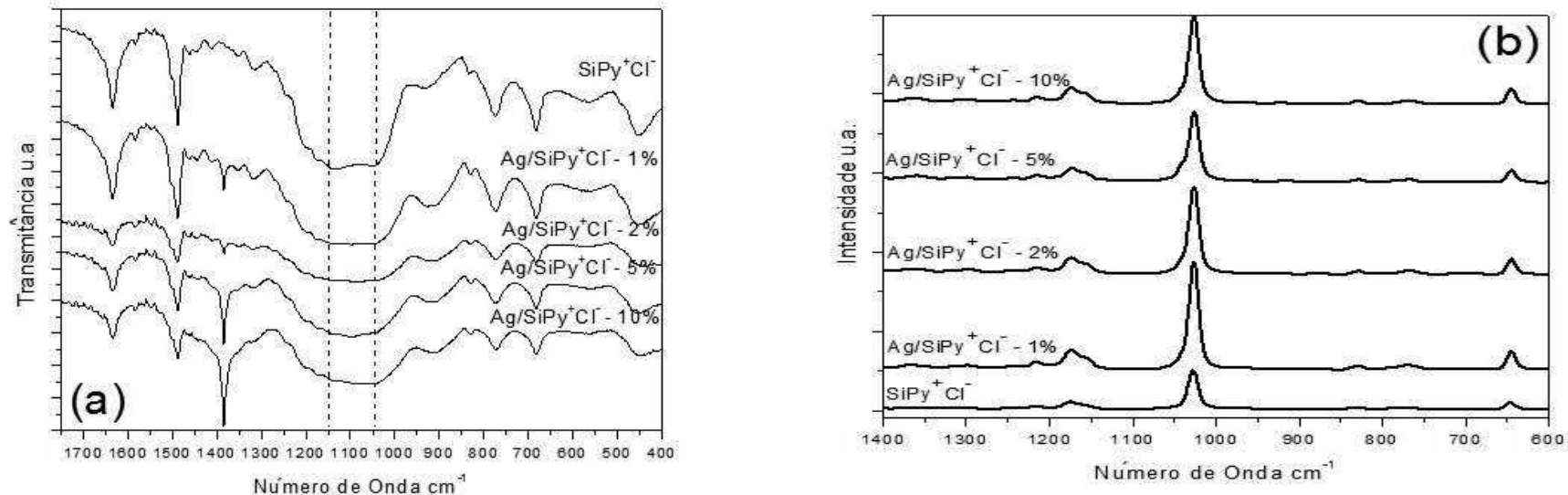

Publ. UEPG Exact Earth Sci., Agr. Sci. Eng., Ponta Grossa, 18 (1): 39-50, jan/jun. 2012

Disponivel em <http://www.revistas2.uepg.br/index.php/exatas> 
No espectro FTIR do $\mathrm{SiPy}^{+} \mathrm{Cl}^{-}$, pode-se observar que as bandas características em $452 \mathrm{~cm}^{-1}$ relativa à deformação angular da ligação Si-O-Si, 775 $\mathrm{cm}^{-1}$ do estiramento simétrico Si-O-Si, 1055 e 1138 $\mathrm{cm}^{-1}$ atribuídas ao estiramento assimétrico Si-O-Si, 1634 e $1484 \mathrm{~cm}^{-1}$ relativas às vibrações do anel piridínio (SANTOS et al., 2012). As duas bandas em 1055 e $1138 \mathrm{~cm}^{-1}$ que estão relacionadas com estiramento assimétrico do grupo Si-O-Si sofreram uma expansão provavelmente causada pela incorporação das AgNPs nas cavidades do $\mathrm{SiPy}^{+} \mathrm{Cl}^{-}$, que altera seu efeito de vibração, devido a inserção das AgNPs nas cavidades do $\mathrm{SiPy}^{+} \mathrm{Cl}^{-}$. (SANTOS et al., 2012). Pode ser observada uma nova banda em $1383 \mathrm{~cm}^{-}$ ${ }^{1}$, referente às vibrações do grupo $\mathrm{NO}_{3}$ (THEIVASANTHI; ALAGAR, 2011; EL-KHESHEN; GAD EL-RAB, 2012; GAJBHIYE et al., 2009), precursor utilizado na síntese. Houve também um decréscimo na intensidade das bandas em 1634 e $1484 \mathrm{~cm}^{-1}$ referentes às vibrações do anel piridínio após a incorporação das nanopartículas. No trabalho de (SANTOS et al., 2012) encontramos resultados semelhantes, com o crescimento de nanopartículas de platina nas cavidades do $\mathrm{SiPy}^{+} \mathrm{Cl}^{-}$, em que as bandas em $1055 \mathrm{e}$ $1138 \mathrm{~cm}^{-1}$ desaparecem na presença das nanopartículas de platina.

Os espectros Raman do $\mathrm{SiPy}^{+} \mathrm{Cl}^{-}$e dos nanocompósitos $\mathrm{Ag} / \mathrm{SiPy}^{+} \mathrm{Cl}^{-}$apresentaram bandas em $1028 \mathrm{~cm}^{-1}$ (forte) e $648 \mathrm{~cm}^{-1}$ (média), atribuídas, respectivamente ao modo de respiração do anel de piridina e à deformação do plano do anel (SANTOS et al., 2012). Comparando-se os espectros das amostras $\mathrm{SiPy}^{+} \mathrm{Cl}^{-}$e $\mathrm{Ag} / \mathrm{SiPy}^{+} \mathrm{Cl}^{-}$, pode-se constatar que as bandas do $\mathrm{SiPy}^{+} \mathrm{Cl}^{-}\left(1028 \mathrm{~cm}^{-1}\right.$ e $\left.648 \mathrm{~cm}^{-1}\right)$ aparecem mais intensas na presença das nanopartículas de prata (SANTOS et al., 2012).

O difratograma (Fig. 4) mostra o DRX feito para as amostras liofilizadas contendo 5\% e 10\% de prata. Podemos notar três picos intensos em $2 \theta=$ $38^{\circ} ; 45,44^{\circ} ; 64,46^{\circ}$ e $77^{\circ}$, que são indexados aos planos (111), (200), (220) e (311) da estrutura cúbica de face centrada da prata (MALLIKARJUNA et al., 2011; SAHA et al., 2011). Os dados obtidos foram comparados com o Joint Committee on Powder Diffraction Standards (JCPDS) ficha No.03-0921.
Figura 4 - Difratograma das amostras de $\mathrm{Ag} / \mathrm{SiPy}^{+} \mathrm{Cl}^{-}-5 \%$ e $\mathrm{Ag} / \mathrm{SiPy}^{+} \mathrm{Cl}^{-}-10 \%$.

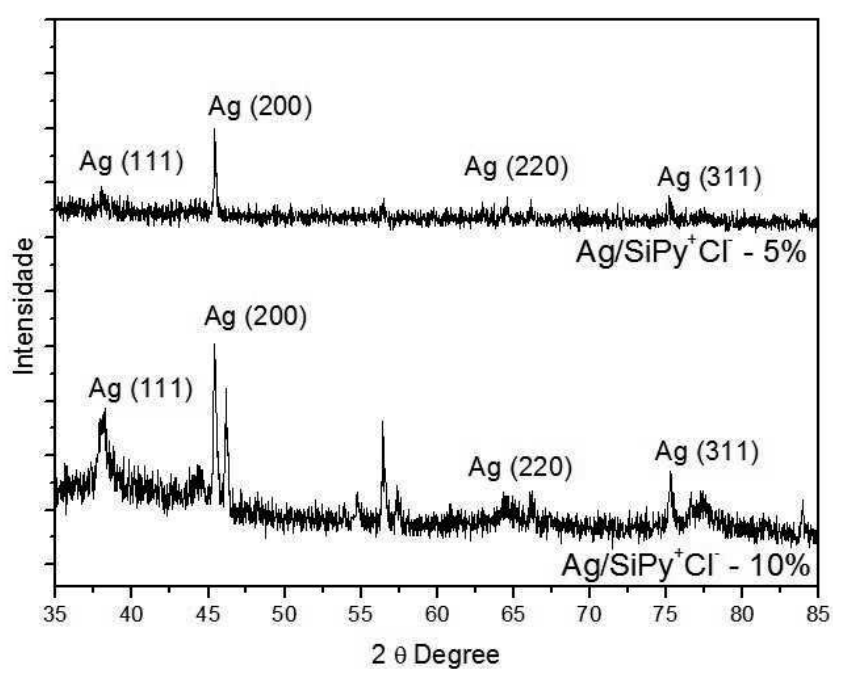

Os picos referentes à prata foram observados $\mathrm{e}$ indexados, no difratograma da amostra $\mathrm{Ag} / \mathrm{SiPy}^{+} \mathrm{Cl}^{-}$ $10 \%$ também foram observados alguns picos que não foram identificados os quais podem estar relacionados à impureza da amostra. $\mathrm{O}$ tamanho médio de cristalito das amostras foi calculado com base no padrão de DRX, utilizando a equação de Scherrer (Equação 2) (DARROUDI et al., 2011):

$$
D_{h k l}=\frac{K \lambda}{\beta \cos (\theta)}
$$

onde, $\mathrm{K}$ é uma constante que depende da forma das partículas (esfera $=0,94) \beta$ representa a largura do pico mais intenso a meia altura, pico (200), $\lambda$ é o comprimento de onda para $\operatorname{CuK} \alpha(\lambda=0.15418 \mathrm{~nm})$ e D é o tamanho do cristalito em nanômetros. $\mathrm{O}$ tamanho médio dos cristalitos foi calculado em $42 \mathrm{~nm}$ para as amostras com $10 \%$ de prata e $48 \mathrm{~nm}$ para as amostras com $5 \%$ de prata. Os valores encontrados para o tamanho médio dos cristalitos foram próximos aos encontrados para as partículas através das medidas de Potencial Zeta após a liofilização.

\section{Incorporação do $\mathrm{Ag} / \mathrm{SiPy}^{+} \mathrm{Cl}^{-}$em tecidos de algodão}

Para o crescimento dos filmes LbL contendo $\mathrm{Ag} / \mathrm{SiPy}^{+} \mathrm{Cl}^{-}$, realizou-se primeiramente um tratamento químico na sua superfície dos tecidos com o objetivo de gerar grupos carboxilatos e melhorar a interação entre o tecido e o nanocompósito $\mathrm{Ag} /$ 
$\mathrm{SiPy}^{+} \mathrm{Cl}^{-}$. Para esse tratamento utilizou-se os ácidos $\mathrm{HNO}_{3}$ e $\mathrm{H}_{3} \mathrm{PO}_{4}$ na concentração de $0,1 \mathrm{~mol} \cdot \mathrm{L}^{-1} \mathrm{e}$ $\mathrm{NaNO}_{2} 1,4 \%(\mathrm{~m} / \mathrm{V})$ Essas proporções foram utilizadas com base em (KUMAR; YANG ,2002) pois segundo esses autores, é a proporação que gera maior quantidade de grupos carboxilatos. A concentração dos ácidos foi escolhida de forma que apenas a superfície do tecido fosse oxidada. Este fato foi confirmado pela espectroscopia FTIR, conforme a Figura 5 , onde o espectro do tecido de algodão puro não foi modificado e não apresentou novas bandas após o tratamento químico, realizado em baixas concentrações dos reagentes.
Ambos os espectros, das Figuras 5a e 5b, apresentaram bandas em aproximadamente 3200 a 3500 $\mathrm{cm}^{-1}$ referentes à ligação $\mathrm{O}-\mathrm{H}, 3000 \mathrm{a} 2800 \mathrm{~cm}^{-1}$, ao estiramento $\mathrm{C}-\mathrm{H}, 1600 \mathrm{~cm}^{-1}$ à água intersticial ou adsorvida, 1450 a $1350 \mathrm{~cm}^{-1}$ à deformação angular C-H e à uma absorção complexa em $1250-900 \mathrm{~cm}^{-}$ 1 , à qual está ligada ao estiramento dos grupos C-O-C (KUMAR; YANG, 2002; UDDIN et al., 2007). No trabalho de (KUMAR; YANG, 2002) foi observada uma banda em aproximadamente $1700 \mathrm{~cm}^{-1}$ referente ao estiramento da ligação $\mathrm{C}=\mathrm{O}$, no caso desta pesquisa, esta banda não foi observada, esse fato pode estar ligado às condições de tratamento do tecido, às quais foram realizadas em condições amenas.

Figura 5 - Espectro FTIR para as amostras de (a) algodão puro e (b) algodão tratado quimicamente.

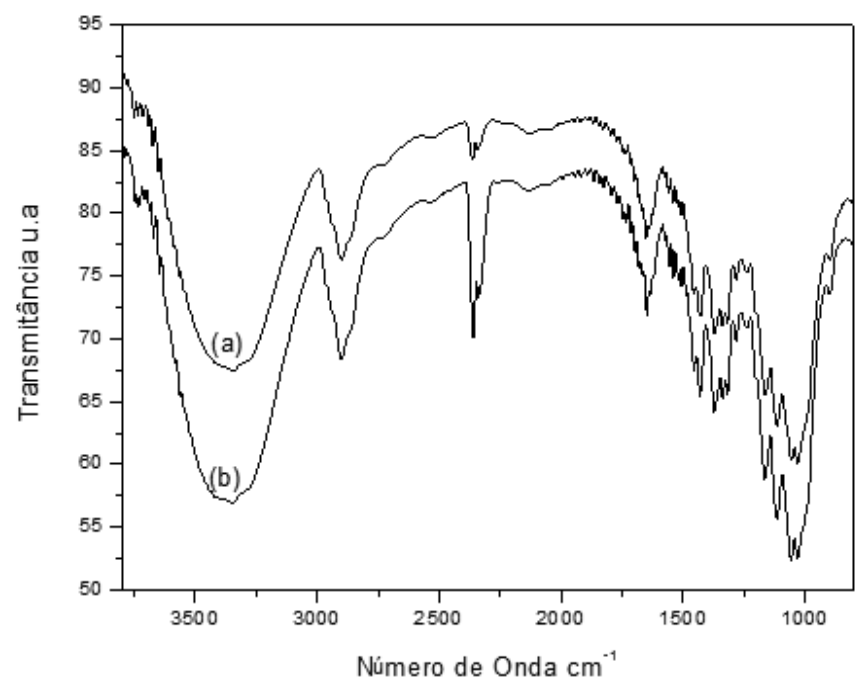

Figura 6 - Imagens de MEV obtidas para (a) algodão puro, (b) algodão tratado quimicamente, (c) algodão com 10 bicamadas do nanocompósito $1 \%-\mathrm{Ag} / \mathrm{SiPy}^{+} \mathrm{Cl} / \mathrm{PSS}$, (d) algodão com 10 bicamadas do nanocompósito $2 \%-\mathrm{Ag} / \mathrm{SiPy}^{+} \mathrm{Cl}^{-} /$ PSS, (e) algodão com 10 bicamadas do nanocompósito 5\%- $\mathrm{Ag} / \mathrm{SiPy}^{+} \mathrm{Cl}^{-} / \mathrm{PSS}$, (f) algodão com 10 bicamadas do nanocompósito $10 \%-\mathrm{Ag} / \mathrm{SiPy}^{+} \mathrm{Cl}^{-} / \mathrm{PSS}$.
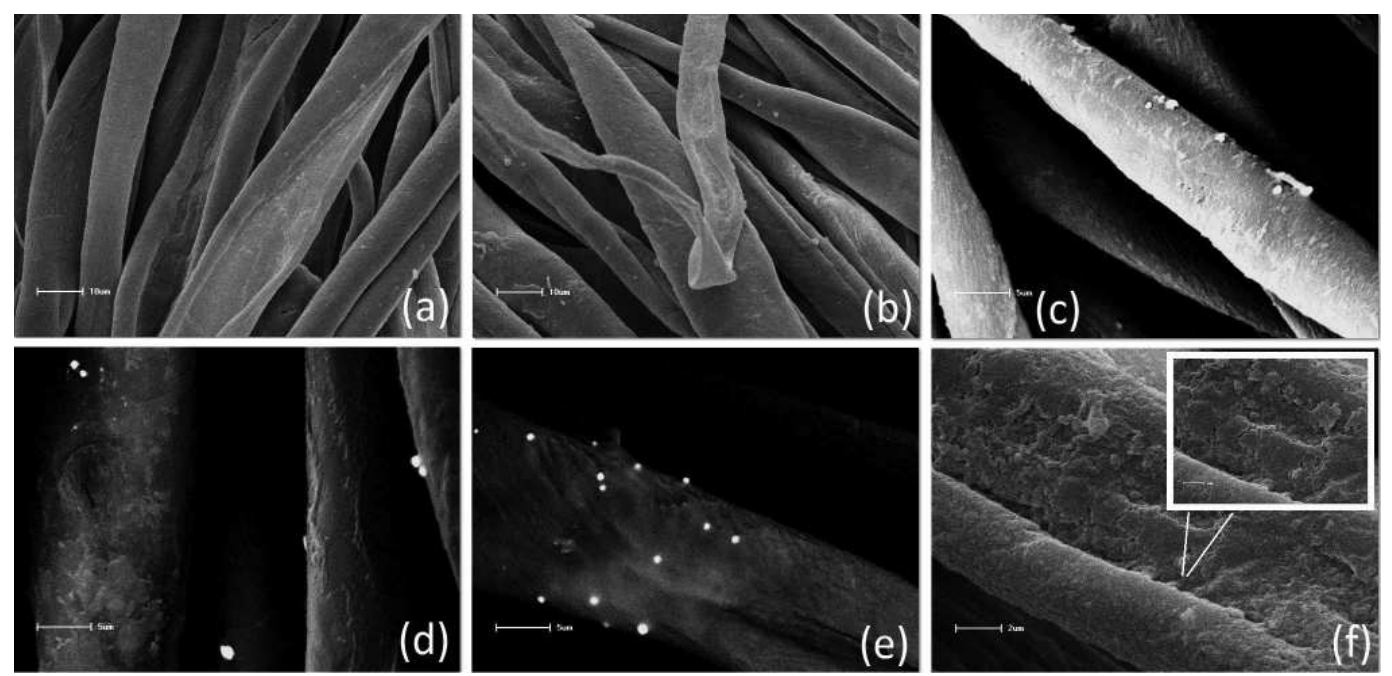

Publ. UEPG Exact Earth Sci., Agr. Sci. Eng., Ponta Grossa, 18 (1): 39-50, jan/jun. 2012

Disponível em <http://www.revistas2.uepg.br/index.php/exatas> 
Além disso, as vibrações observadas estão relacionadas aos grupos do interior da fibra, pois devido ao seu diâmetro $(\sim 10 \mu \mathrm{m})$, a contribuição de grupos em sua superfície é muito pequena ou insignificante. Isso pode ser observado nos espectros da fibra de algodão puro comparando-a com o espectro da fibra tratada quimicamente, os quais se mantêm inalterados (KUMAR; YANG, 2002; UDDIN et al., 2007). Isso significa que devido à pequena área superficial externa das fibras, o espectro FTIR nos mostra que o tratamento químico no algodão atinge apenas a superfície do tecido, provando assim, que a composição interna das fibras do tecido não é alterada. Embora o tratamento químico gere uma mudança na estrutura química da superfície do tecido, ele não alterou a estrutura de suas fibras, como pode ser observado nas imagens de MEV (Figura 6), onde as fibras de algodão puras (Figura 6a) não apresentam diferença significativa comparada às fibras tratadas quimicamente (Figura 6b). Nas imagens das Figuras 6(c)-(f) podem-se observar as fibras de algodão com 10 bicamadas do compósito $\mathrm{Ag} / \mathrm{SiPy}^{+} \mathrm{Cl} / \mathrm{PSS}$ com $1,2,5$ e $10 \%$ de prata respectivamente.

Com base nas Figuras 6(a) e 6(b), observa-se que as fibras de algodão sem e com tratamento se apresentam lisas sem nenhum tipo de revestimento. Por outro lado nas Figuras 6(c)-(f), as fibras de algodão aparecem revestidas por filme fino e uniforme basicamente formado pelo nanocompósito com as nanopartículas de prata. Observa-se ainda que à medida que se aumenta a porcentagem de prata no nanocompósito, o filme se apresenta mais espesso (zoom Figura 6(f)) e também com maior quantidade de nanopartículas de prata em sua superfície.

Já existem na literatura imagens semelhantes da impregnação de nanopartículas de prata a materiais têxteis (FEITOR, 2010; DASTJERDI; MONTAZER, 2010; EL-RAFIE et al., 2012; ILIC et al., 2009; CHEN; CHIANG, 2008; NOURBAKHSH; ASHJARAN, 2012; GUPTA et al., 2008; RISTIC et al., 2011). Porém, o método utilizado nesta pesquisa baseia-se da adsorção eletrostática do nanocompósito na superfície, o que promete uma interação mais forte e assim uma maior durabilidade do tecido.

Análise da atividade antimicrobiana dos tecidos modificados com filmes LbL PS Cell-Ag/ $\mathrm{SiPy}^{+} \mathrm{Cl}^{-}$
Com as amostras de tecidos Cell- $\mathrm{Ag} / \mathrm{SiPy}^{+} \mathrm{Cl}^{-}$ criadas com 10 bicamadas do nanocompósito nas concentrações de $1 \%, 2 \%, 5 \%$ e $10 \%$ foram realizadas avaliações de atividade antimicrobiana pelos tecidos modificados.

A inibição da atividade microbiana pode ser dada por dois efeitos: bacteriostático e bactericida. Entende-se por efeito bacteriostático aquele que promove inibição do crescimento bacteriano. O efeito bactericida corresponde à lise e à morte celular. Desta forma, quando da presença de um efeito bacteriostático, o crescimento bacteriano deverá ocorrer após a retirada do agente biocida; enquanto que, no caso de um efeito bactericida, a retirada deste agente não é suficiente para promover o crescimento bacteriano, uma vez que este induz à morte celular.

Para avaliar o efeito biocida no tecido modificado, as atividades antimicrobianas foram testadas em meio de cultura rico sólido e líquido, Luria Broth. Primeiramente, os tecidos puros e modificados foram incubados em meio líquido LB, previamente inoculados com uma colônia isolada de $E$. coli estirpe DH5 $\alpha$, e a densidade óptica foi avaliada após 24 e 48 horas de crescimento (Figura 7).

Figura 7 - Densidade Ótica a $600 \mathrm{~nm}$ das amostras de algodão puro e $E$. coli estirpe DH5 $\alpha$ (controle positivo) e algodão contendo $1 \%, 2 \%, 5 \%$, e $10 \%$ de nanopartículas de prata.

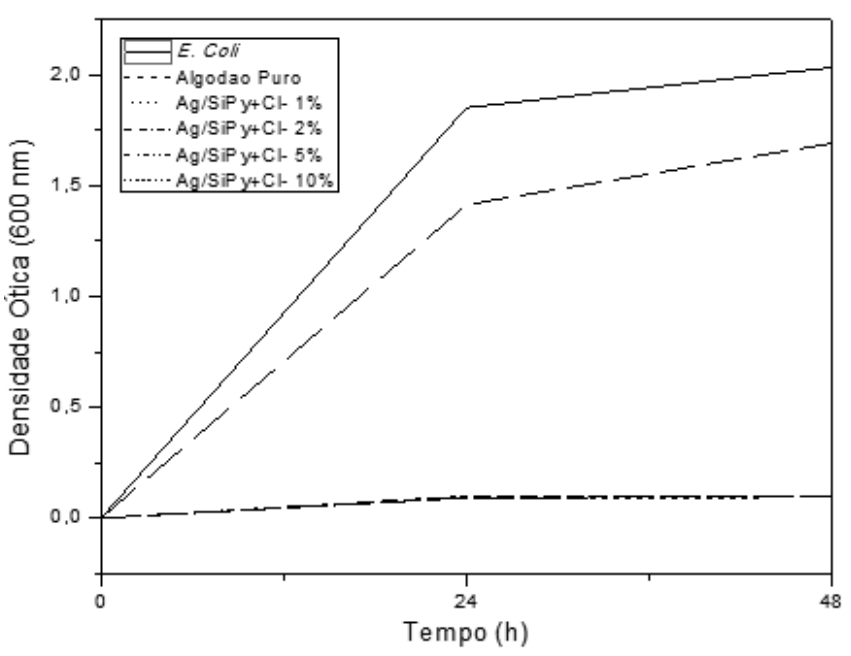


Todas as amostras de tecido que continham prata incorporada não tiveram um aumento significativo na absorção ótica em $600 \mathrm{~nm}$, devido a este fato, os espectros estão sobrepostos, indicando a inibição do crescimento bacteriano promovido por esta modificação por até 48 horas. Como os tecidos inoculados não foram esterilizados previamente, muitos organismos da própria flora epitelial e do ambiente poderiam ter se desenvolvido, uma vez que o meio de cultura utilizado tratava-se de um meio rico. Entretanto, não foi evidenciada a formação de nenhuma outra espécie, mesmo após $48 \mathrm{~h}$, indicando um efeito inibitório, de amplo espectro.
Para avaliação do tipo de efeito biocida, as amostras dos frascos crescidos na presença dos tecidos foram reinoculadas em meio sólido LA. Após crescimento a $37^{\circ} \mathrm{C}$ durante $24 \mathrm{~h}$, não foi evidenciada nenhuma formação de unidades formadoras de colônias, em comparação ao crescimento a partir da amostra que continha o algodão puro (controle positivo) $(\mathrm{S} / 1, \mathrm{~S} / 2$ e $\mathrm{S} / 3)$ figura 8 . Esse resultado sugere que as nanopartículas de prata exerceram um efeito bactericida sobre E. coli, uma vez que mesmo na ausência do tecido, não ocorreu o crescimento bacteriano.

Figura 8 - Semeadura em meio sólido LA das amostras cultivadas em meio líquido LB após 24 horas de incubação. Controle Positivo: Amostras com algodão puro (S/1, S/2 e S/3); as legendas Ag 1\%, 2\%, 5\% e 10\% tratam-se de triplicatas de amostras de tecido contendo as nanopartículas de prata nas concentrações de $1 \%, 2 \%, 5 \%$ e $10 \%$, respectivamente.

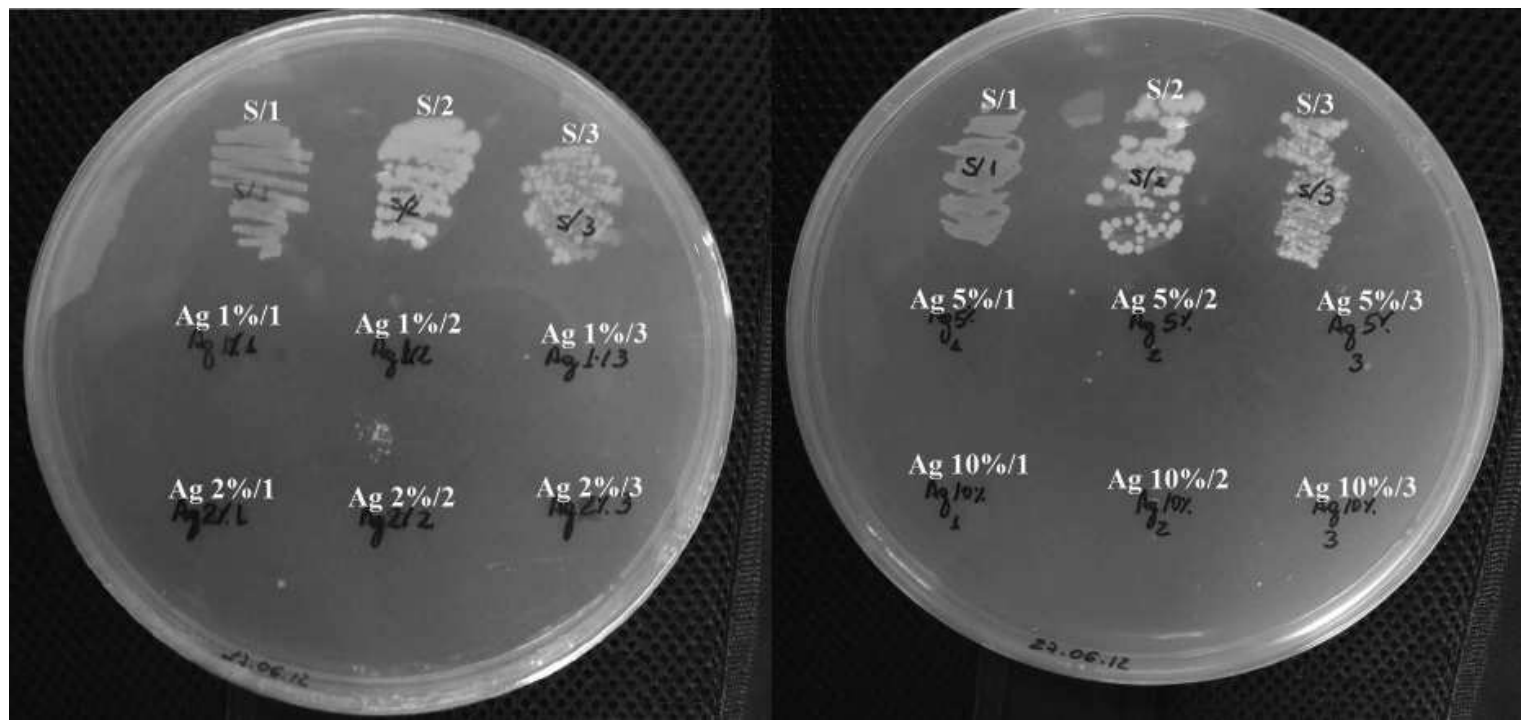

Como já estudado na literatura, a prata nanoparticulada possui uma ação biocida muito mais pronunciada devido a sua maior área superficial. Alguns estudos também mostram uma menor eficiência da ação biocida com as nanopartículas de prata, o que pode estar ligado à quantidade de prata impregnada no tecido ou ao tamanho das partículas (CHEN; CHIANG, 2008; NOURBAKHSH; ASHJARAN, 2012; GUPTA et al., 2008; RISTIC et al., 2011). Os resultados obtidos neste trabalho indicam que o tecido modificado com as nanopartículas de prata exerce um efeito bactericida sobre E. coli DH5 $\alpha$ e é capaz de inibir o crescimento bacteriano e fúngico em amplo espectro.

\section{Conclusão}

A síntese das nanopartículas de prata no polieletrólito cloreto de 3-n propilpiridínio silsesquioxano $\left(\mathrm{SiPy}^{+} \mathrm{Cl}^{-}\right)$utilizado como nanoreator para o crescimento controlado das nanopartículas foi realizado com sucesso, uma vez que as nanopartículas tiveram um tamanho médio de $18-40 \mathrm{~nm}$, com uma alta estabilidade das suspensões. $\mathrm{O}$ tratamento químico na superfície do tecido foi realizado para melhorar a interação do nanocompósito com as moléculas na superfície do tecido, a partir dos grupos carboxilatos gerados, as fibras desse tecido não sofreram qualquer tipo de agressão, fato confirmado 
pela espectroscopia FTIR e as imagens de MEV das fibras. O método Layer-by-Layer mostrou-se eficaz para o propósito desse trabalho, pois com o tratamento químico da superfície, o tecido passou a adsorver eletrostaticamente o nanocompósito com as nanopartículas de prata.

Os testes biocidas realizados na presença de uma colônia $E$. coli estirpe DH5 $\alpha$, apresentaram resultados promissores, pois mostraram uma alta atividade bacteriostática e uma atividade bactericida, mostrando ser eficiente para uma ampla variedade de micro-organismos. Concluímos que este método de impregnação de nanopartículas na fibra de tecidos é uma boa alternativa para produção de tecidos com propriedades antimicrobianas.

\section{Referências}

CHEN, C.; CHIANG, C. Preparation of cotton fibers with antibacterial silver nanoparticles. Materials Letters, v. 62, p. 3607-3609, 2008,

DARROUDI, M. et al. Fabrication and characterization of gelatin stabilized silver nanoparticles under UV-Light. International Jornaul of Molecular Sciences, v. 12, p 6346-6356, 2011.

DASTJERDI, R.; MONTAZER, M. A review on the application of inorganic nano-structured materials in the modification of textiles: Focus on anti-microbial properties. Colloids and Surfaces B: Biointerfaces, v. 79, p 5-18, 2010.

DECHER, G. et al. Proof of multilayer structural organization in self-assembled polycation-polyanion molecular films. Thin Solid Films, v. 244, p.772-777, 1994.

EL-KHESHEN, A. A.; GAD EL-RAB, S. F. Effect of reducing and protecting agentes o size of silver nanoparticles and their anti-bacterial activity. Scholars Research Library, v. 4 (1), p. 53-65, 2012.

EL-RAFIE, M.H. et al. Bio-synthesis and applications of silver nanoparticles onto cotton fabrics. Carbohydrate Polymers, v. 90, p 915-920, 2012.

FEITOR, M. C. Efeito antibacteriano de tecidos têxteis revestidos por prata através da técnica de deposição por plasma. 2010, $116 \mathrm{f}$. Tese (Doutorado em Ciência e Engenharia de Materiais) - Universidade Federal do Rio Grande do Norte, Natal, 2010.

GAJBHIYE, M. et al. Fungus-mediated synthesis of silver nanoparticles and their activity against pathogenic fungi in combination with fluconazole. Nanomedicine: Nanotechnology, Biology, and Medicine, v. 5, p. 382-386, 2009.
GARCIA, M. V. D. Síntese, caracterização e estabilização de nanopartículas de prata para aplicações bactericidas em têxteis. 2011, 77 f. Dissertação (Mestrado em Engenharia Química) - Faculdade de Engenharia Química, Universidade de Campinas, Campinas, 2011.

GUPTA, P. et al. Investigation of antibacterial properties of nanoparticle-loaded poly (acrylamide-co-itaconic acid)grafted cotton fabric. The Journal of Cotton Science, v. 12, p. 280-286, 2008,

ILIC, V. et al. The influence of silver content on antimicrobial activity and color of cotton fabrics functionalized with $\mathrm{Ag}$ nanoparticles. Carbohydrate Polymers, v. 78, p. 564-569, 2009.

KUMAR, V.; YANG, T. HNO3/H3PO4 - NaNO2 mediated oxidation of celulose - preparation and characterization of bioabsorbable oxidized celluloses in high yields and with diferente levels of oxidation. Carbohydrate Polymers, v. 48, p. 403-412, 2002.

LIU, J. et al. Preparatin of high concentration of silver colloidal nanoparticles in layered laponite sol. Colloids and Surfaces A: Physicochem. Eng. Aspects, v. 302, p. 276279, 2007.

MALLIKARJUNA, K. et al. Green synthesis of silver nanoparticles using ocimum leaf extract and their characterization. Digest Journal of Nanomaterials and Biostructures, v. 6, n. 1, p. 181- 186, January-March, 2011,

NETO, E. A. B. Desenvolvimento de nanobiocompósitos contendo nanopartículas de prata para aplicações bactericidas. 2010, 112 f. Dissertação (Mestrado em Ciências) - Instituto de Física, Universidade de São Paulo, São Carlos, 2010.

NOURBAKHSH, S.; ASHJARAN, A. Laser Treatment of Cotton Fabric for Durable Antibacterial Properties of Silver Nanoparticles. Materials,v. 5, p 1247-1257, 2012.

PENG, Y. et al. Bottom-up nanoconstruction by the welding of individual metallic nanoobjects using nanoscale solder. Nano Lett, v. 9, p. 91-96, 2009.

RISTIC, T. et al. Animicrobial Efficiency of functionalized celulose fibres as potential medical textiles. Science against microbial pathogens: communicating current research and technological advances A. Méndez-Vilas (Ed.), 2011.

SAHA, S. et al. Preparation of silver nanoparticles by bioreduction using nigrospora oryzae culture filtrate and its antimicrobial activity. Digest Journal of Nanomaterials and Biostructures, v. 6, n. 4, October-December, 15191528, 2011.

SANTOS, V. et al. Platinum nanoparticles incorporated in silsesquioxane for use in LbL films for the simultaneous detection of dopamine and ascorbic acid. Jornal of Nanoparticle Research, v. 14 p. 1081, 2012. 
SCHAFFAZICK, S. R. et al. Caracterização e estabilidade físico-química de sistemas poliméricos nanoparticulados para administração de fármacos. Quím. Nova, São Paulo, v. 26 , n. 5 , Oct. 2003.

SONG, K. C. et al. Preparation of colloidal silver nanoparticles by chemical reduction method. Korean $\mathbf{J}$. Chem. Eng., v. 26(1), p. 153-155, 2009.

THEIVASANTHI, T.; ALAGAR, M. Electrolytic synthesis and characterizations of silver nanopowder. General Physics, Nov, 2011.

UDDIN, M. J. et al. Photoactive TiO2 films on cellulose fibres: synthesis and characterization. Journal of Photochemistry and Photobiology A: Chemistry, v. 189, p. 286-294, 2007.

Recebido em 26/02/2013

Aceito em 17/04/2013 